\title{
A Validation Study of the Korean Version of the Connectedness to Nature Scale
}

\author{
Wan-Suk Gim ${ }^{1}$, Min-Hyung Lee ${ }^{1 *}$, and Kwang-Hyune Kim² \\ ${ }^{1}$ Department of Psychology, Ajou University, Suwon 16499, Korea \\ ${ }^{2}$ Department of Buddhist Studies, Seoul University of Buddhism, Seoul 08559, Korea
}

\section{ABSTRACT}

The purpose of this study was to investigate the reliability and validity of the Korean version of the Connectedness to Nature Scale(K-CNS), which was translated from the Connectedness to Nature Scale(CNS) developed by Mayer and Frantz. For this study, questionnaires were conducted with a sample of 407 Korean citizens from various backgrounds and regions, with the ages ranging from 17 to 60. Exploratory factor analysis, internal consistency test and correlation checks were conducted on this questionnaires data. The results of exploratory factor analysis supported that the K-CNS has 10 items in a single factor. The internal consistency of the K-CNS was .880. The K-CNS was positively correlated to the NEP (New Environmental Paradigm), satisfaction with life, mental health, compassionate love, and negatively correlated to stress response. In addition, differences were found by group and age, but not by the gender. The K-CNS was higher in the natural-friendly group than in the general group. By age, the K-CNS scores was high in 40s and 50s than 10-39 years old.

Keywords: exploratory factor analysis, measure, nature connectedness

\section{Introduction}

Human beings have long been using nature to cure physical and mental illnesses (Louv, 2011). Researchers that had interest in the increase of mental illnesses due to urbanization have been seeking the possibility of using the natural environment in relieving stress and treating psychological disorders. They assumed that recovery through contact with nature and nature connection would promote well-being and mental health (Bratman et al., 2012; Pretty, 2004). Recent studies prove that nature connectedness promotes subjective well-being, positive emotions and positive relationships, while also reinforcing the capacity for mindfulness that improves self-perception, self-esteem and recuperative powers (Coholic, 2011).

Nature connectedness refers to 'connection of humans with nature as one' and is a concept discussed in various aspects among different scholars. Schultz (2002) stated that the concept of nature connectedness expands one's identity to nature, and Dunlap and Van Liere (1978) approached nature connectedness from the perspective of the New Environmental Paradigm (NEP). This is contrary to the anthropocentric view of nature, which is the dominant paradigm of the Western society, claiming that humans and the nature are equals and that there is a close correlation between the two, or even regarding humans as beings that belong to nature. Nisbet (2009) perceived nature connected as 'myself in the ecosystem', which is a part of nature, and Mayer and Frantz (2004) briefly determined nature connectedness as an emotional feeling connected to nature.

As such, various measures and scales have been developed along with empirical research on the connection between humans and nature, and each of them has its own characteristics. The NEP scale measures the fundamental

Received: August 7, 2019, Revised: September 6, 2019, Accepted: November 25, 2019

First author: Wan-Suk Gim, wsgimajou@gmail.com, (D) https://orcid.org/0000-0002-7944-1751

*Corresponding author: Min-Hyung Lee, wethink3@gmail.com, (10) https://orcid.org/0000-0001-8792-8335 
belief about the relationship between nature and oneself (Dunlap et al., 2000) and the Nature Relatedness Scale (NRS) measures the relationship between humans and nature in the emotional, cognitive and empirical aspects (Nisbet et al., 2009). The Connectedness to Nature Scale (CNS) is developed by Mayer and Frantz (2004) and performs an in-depth measurement of the emotional feeling of being connected to nature.

Despite the existing scales to measure the relationship with nature, validation of the Korean version of the CNS is necessary for the following reasons. First, it is to closely capture the emotional and empirical connectedness of individuals about 'unity with nature'. Second, the therapeutic effects of nature are closely related to the emotional aspect such as recovering emotions, promoting well-being and relieving stress (Bratman et al., 2015; Sahlin, 2014; Sahlin et al., 2014), and they need various scales to more elaborately measure the emotional effects. Finally, the CNS is currently in the English version that is randomly translated and revised by researchers, without systematic validation in Korea.

Therefore, this study is to translate 14 items of the CNS developed by Mayer and Frantz (2004) in Korean and develop the Korean version of the Connectedness to Nature Scale (K-CNS) with reliability and validity.

\section{Research Methods}

\section{Subjects}

For extensive and diverse samples, we conducted a survey on total 407 citizens aged 17 to 60 living in Suwon-si of Gyeonggi-do, Hongseong-gun of Chungcheongnam-do, and Jeonju-si of Jeollabukdo, twice from April to September 2017.

\section{Tools}

\section{K-CNS confirmation process}

Two researchers translated the English text of the 14 items of the CNS into Korean, which were mutually reviewed and revised afterwards. The revised items were then reviewed by three doctors of psychology and one doctor of English literature, seeking advice in terms of appropriacy of translation. After that, the items were backward translated by a doctor of English literature fluent in both languages, and the backward translated items were compared to the original. The researchers discussed the items with inconsistent meanings as a result of comparison, after which the final translation of the items was completed.

\section{Evaluation tools}

To secure construct validity, we selected the NEP scale that measures the attitude toward nature and world view as well as scales related to satisfaction with life, well-being, stress and compassion that are known to be variables closely related to contact with nature, and then analyzed the correlation among them. More specifically, we selected the tools based on previous research that nature connectedness has positive effects on protecting the ecological environment and respecting the biosphere (Mayer and Frantz, 2004), as well as research proving that nature is closely correlated to satisfaction with life, well-being and compassion while also relieves stress (Coholic, 2011; Sahlin, 2014; Lumber et al., 2017).

(1) Korean version of the Connectedness to Nature Scale (K-CNS)

The K-CNS is developed by translating the items of the CNS by Mayer and Frantz (2004) into Korean. Cronbach's alpha of the K-CNS turned out to be .880 . The CNS developed by Mayer and Frantz (2004) is comprised of 14 items in a single factor measuring how much humans feel as if they are part of nature, rated on a 5-point scale, and Cronbach alpha was .84 . The results are evaluated by the sum of the items, and items 4,12 , and 14 are reversed items.

(2) New Environmental Paradigm (NEP)

The NEP developed by Dunlap and Van Liere (1978) is comprised of 12 items in two factors measuring the psychological attitudes of individuals toward nature, rated on a 4-point scale. The scale used in this study is the Korean version validated by Shin et al. (2001). It is comprised 
of three factors such as 'humans over nature', 'balance of nature' and 'limits of growth', and Cronbach alpha was .69. The results are evaluated by the sum of the items, and items 5, 6, 7, and 11 are reversed items.

\section{(3) Satisfaction With Life Scale (SWLS)}

The SWLS developed by Diener, Emmons, Larsen and Griffin (Diener et al., 1985) is comprised of 5 items measuring people's satisfaction with life, rated on a 7-point scale. This study used the scale translated by Cho and Cha (1998). The internal consistency reliability or Cronbach alpha was .84.

(4) Mental Health Continuum-Short Form (MHC-SF)

The MHC-SF developed by Keyes (2002) is comprised of 14 items in three factors evaluating mental well-being on a 6-point scale. It evaluates three aspects: emotional, psychological, and social well-being. This study used the scale translated by Lim et al. (2012), and Cronbach alpha was .93 .

(5) Modified form of the Stress Response Inventory (SRI-MF)

The SRI-MF developed by Choi et al. (2006) is comprised of 22 items measuring the major responses to stress in terms of cognitive, emotional, behavioral and physical responses, rated on a 5-point scale. It has three factors such as physical body, depression and anger, and the internal consistency reliability is stable at $\mathbf{. 9 3}$.

(6) Ajou Compassionate Love Scale (ACLS-CO)

The CLS is developed by Sprecher and Fehr (2005) to measure compassionate love, evaluating "feelings, cognitions, and behaviors that are focused on caring, concern, tenderness, and an orientation toward supporting, helping, and understanding the other(s)". This study used the ACLS-CO shortened by Gim and Shin (2014). It is comprised of 12 items in a single factor rated on a 7-point scale, and the internal consistency reliability was .91.

\section{Analysis method}

Data collected in this study were analyzed by conducting one-way ANOVA and t-test using the statistical program IBM SPSS Statistics 22 version (IBM Corp., Armonk, NY, USA). An exploratory factor analysis was conducted to verify the cross-cultural validity of the items of the K-CNS.

\section{Results and Discussion}

\section{Exploratory factor analysis}

An exploratory factor analysis was conducted to verify the factor structure of the K-CNS. The suitability of the samples was verified by the KMO (kaiser-Meyer-Olkin) and turned out to be .898 , thereby suitable. As a result of primary analysis through maximum-likelihood classification and direct oblimin, there were three factors with 'Eigenvalues 1 or higher' (Factor 1: 5.217, Factor 2: 1.315, Factor 3: 1.221). The items were grouped as follows: 11 items in Factor 1, one item in Factor 2 (item No. 12), and two items in Factor 3 (item No. 4, 14). Considering that Factors 2 and 3 have few items to form a factor, and that the decline between Factors 1 and 2 was the greatest as a result of the scree test, it was found that the solution of Factor 1 would be suitable. Therefore, as a result of analysis by fixing the number of factors as one, the commonality of the four items (item No. 4, 12, 13, 14) was low at .154-.207, and the total score of items and factor loading were also low at .4 or lower (Table 1). Based on this, 10 items were finally selected. As a result of conducting a factor analysis with 10 items in one factor, the variance explained was $43.64 \%$ and the factor loading was between .474 and .804 , thereby suitable.

\section{Reliability analysis}

As a result of conducting item analysis and reliability analysis on the 10 items selected with exploratory factor analysis, the item total correlation was .464 to .732 , thereby favorable. Moreover, the reliability of the K-CNS was satisfactory with Crohenbach alpha at .880 , which is similar to .84 reported by Mayer and Frantz (2004) who originally developed the scale. Therefore, the K-CNS can be a suitable scale to use in the Korean culture. 
Table 1. Exploratory factor analysis for Korean version of the Connectedness to Nature Scale (K-CNS) questionnaire items

\begin{tabular}{|c|c|c|c|c|c|}
\hline $\begin{array}{l}\text { Item } \\
\text { No. }\end{array}$ & Question & $\begin{array}{c}\mathrm{M} \\
(\mathrm{SD})\end{array}$ & $\begin{array}{c}\text { Corrected } \\
\text { Item-Total } \\
\text { Correlation }\end{array}$ & $\begin{array}{c}\text { Cronbach's } \\
\text { Alpha if Item } \\
\text { Deleted }\end{array}$ & $\begin{array}{l}\text { Factor } \\
\text { loading }\end{array}$ \\
\hline 1 & I often feel a sense of oneness with the natural world around me. & $\begin{array}{c}3.40 \\
(1.05)\end{array}$ & .687 & .810 & .767 \\
\hline 2 & I think of the natural world as a community to which I belong. & $\begin{array}{c}3.83 \\
(0.96)\end{array}$ & .717 & .809 & .803 \\
\hline 3 & I recognize and appreciate the intelligence of other living organisms. & $\begin{array}{c}4.02 \\
(0.81)\end{array}$ & .528 & .823 & .560 \\
\hline 4 & I often feel disconnected from nature. & $\begin{array}{c}3.50 \\
(0.92)\end{array}$ & .192 & .843 & .230 \\
\hline 5 & $\begin{array}{l}\text { When I think of my life, I imagine myself to be part of a larger cyclical process } \\
\text { of living. }\end{array}$ & $\begin{array}{c}3.31 \\
(0.95)\end{array}$ & .427 & .829 & .500 \\
\hline 6 & I often feel a kinship with animals and plants. & $\begin{array}{c}3.22 \\
(1.06)\end{array}$ & .452 & .827 & .472 \\
\hline 7 & I feel as though I belong to the Earth as equally as it belongs to me. & $\begin{array}{c}3.54 \\
(1.00)\end{array}$ & .553 & .820 & .615 \\
\hline 8 & I have a deep understanding of how my actions affect the natural world. & $\begin{array}{c}3.61 \\
(0.92)\end{array}$ & .554 & .821 & 639 \\
\hline 9 & I often feel part of the web of life. & $\begin{array}{c}3.52 \\
(0.89)\end{array}$ & .693 & .812 & .754 \\
\hline 10 & $\begin{array}{l}\text { I feel that all inhabitants of Earth, human, and nonhuman, share a common 'life } \\
\text { force'. }\end{array}$ & $\begin{array}{c}3.82 \\
(0.99)\end{array}$ & .645 & .814 & .692 \\
\hline 11 & $\begin{array}{l}\text { Like a tree can be part of a forest, I feel embedded within the broader natural } \\
\text { world. }\end{array}$ & $\begin{array}{c}3.89 \\
(0.87)\end{array}$ & .662 & .815 & .711 \\
\hline 12 & $\begin{array}{l}\text { When I think of my place on Earth, I consider myself to be a top member of a } \\
\text { hierarchy that exists in nature. }\end{array}$ & $\begin{array}{c}3.42 \\
(1.10)\end{array}$ & -.016 & .860 & -.037 \\
\hline 13 & $\begin{array}{l}\text { I often feel like I am only a small part of the natural world around me, and that } \\
\text { I am no more important than the grass on the ground or the birds in the trees. }\end{array}$ & $\begin{array}{c}2.97 \\
(1.10)\end{array}$ & .331 & .836 & .339 \\
\hline 14 & My personal welfare is independent of the welfare of the natural world. & $\begin{array}{c}3.89 \\
(0.94)\end{array}$ & .348 & .833 & .366 \\
\hline \multicolumn{6}{|c|}{$\begin{array}{c}\text { Cronbach's alpha: .836; Eigenvalue: Factor } 1 \text { (5.217), Factor } 2 \text { (1.315), Factor } 3 \text { (1.221); } \\
\text { \% of Variance: Factor 1(37.262), Factor } 2 \text { (9.391), Factor } 3 \text { (8.723). }\end{array}$} \\
\hline
\end{tabular}

\section{Validity analysis}

\section{Correlation between K-CNS and other scales}

To test construct validity, we conducted the correlation analysis between the K-CNS and other scales using Spearman's rank-order correlation coefficient.

As shown in Table 2, the K-CNS showed a strong positive correlation with NEP scale, MHC-SF, ACLS-CO, and SWLS, but a negative correlation with the SRI-MF. This is consistent with the findings by Mayer and Frantz (2004) that nature connectedness is positively correlated with protection of the ecological environment and satisfaction with life. Moreover, the result is also consistent with previous studies claiming that nature has a close positive correlation with satisfaction with life, well-being and compassion, while also relieving stress (Coholic, 2011; Sahlin, 2014; Lumber et al., 2017). One thing to note in this analysis is that the K-CNS shows a higher correlation than the NEP in emotion-related scales such as well-being, compassion, satisfaction with life and stress, which implies the significance of developing the scale that can measure the emotional aspect in more detail. 
Table 2. Correlation coefficients between $\mathrm{K}-\mathrm{CNS}$ and other scales $(\mathrm{N}=407)$

\begin{tabular}{ccccccc}
\hline & K-CNS & NEP & MHC-SF & ACLS-CO & SWLS & SRI-MF \\
\hline NEP & $.485^{* *}$ & 1 & & & & \\
MHC-SF & $.392^{* *}$ & $.108^{*}$ & 1 & & & \\
ACLS-CO & $.391^{* *}$ & $.211^{* *}$ & $.351^{* *}$ & .1 & $.279^{* *}$ & 1 \\
SWLS & $.316^{* *}$ & $.076^{\mathrm{NS}}$ & $.606^{* *}$ & $-.159^{* *}$ & $-.346^{* *}$ & 1 \\
SRI-MF & $-.185^{* *}$ & $-.061^{\mathrm{NS}}$ & $-.378^{* *}$ & & \\
\hline
\end{tabular}

Note. $\mathrm{K}-\mathrm{CNS}=$ Korean version of the Connectedness to Nature Scale; NEP= New Environmental Paradigm Scale; MHC-SF= Mental Health Continuum-Short Form; ACLS-CO= Ajou Compassionate Love Scale-Close Acquaintance; SWLS= Satisfaction with Life Scale; SRI-MF= Stress Response Inventory-Modified Form.

${ }^{\mathrm{NS}}$ Non-significant, ${ }^{*} p<.05,{ }^{* *} p<.01,{ }^{* * *} p<.001$ by Nonparametric Correlations (Spearman's rho).

\section{K-CNS and between-group relations}

We conducted an independent samples t-test to verify the differences between the general group (307 subjects) and nature-friendly group (100 subjects: forest therapists, agricultural alternative high school students). The results were $t=-8.063, p<.001$, proving that the nature-friendly group had higher nature connectedness with a significant difference (Table 3). This result is consistent with the general expectation that the group that was closely associated with nature would have higher nature connectedness, and it also coincides with the study by Lee (2013) proving that the group with high forest visit frequency and the group engaged in environment-related activities showed higher K-NRS scores than the general group. Considering that exposure to or experience in nature is closely related to nature connectedness, it seems necessary to make constant efforts to be in contact with nature to improve quality of life. Furthermore, there is recently a growing interest in Green Care, nature-based therapy (NBT) and agro-healing, and related studies are also increasing. Therefore, various programs to promote nature connectedness based on Korea's rich forest resources and long historical traditions of agriculture must be developed to contribute to promoting national health.

\section{K-CNS and between-subgroup relations}

To determine the validity of the K-CNS, we verified the differences in K-CNS by group using all the samples $(\mathrm{N}=407)$. The general group was subdivided into general adults and general high school students, and the na-
Table 3. Verification of K-CNS differences between groups $(\mathrm{N}=407)$

\begin{tabular}{cccccc}
\hline Group & $\mathrm{n}$ & $\mathrm{M}$ & $\mathrm{SD}$ & $t$ & $p$ \\
\hline General & 307 & 34.97 & 6.77 & & \\
Nature-friendly & 100 & 39.83 & 4.58 & -8.063 & $.000^{* * *}$ \\
\hline${ }^{* * *} p<.001$ by Independent Sample t-test.
\end{tabular}

ture-friendly group was subdivided into forest therapists and agricultural alternative high school students. Compared to the general group, the nature-friendly group was comprised of forest therapists involved in nature as an occupation and agricultural alternative high school students engaged in outdoor agricultural training at least 8 hours a week according to the school curriculum.

We used the Welch test since Levene's equality of variance conditions were not met in the test for homogeneity of variance, and we performed the Games-Howell test as a post-hoc test to verify where the differences were found among the four groups. As shown in Table 4, the results showed that the nature-friendly group (forest therapists, agricultural alternative high school students) showed significantly higher K-CNS scores than the general group (general adults, academic high school students). This is consistent with the result of the independent samples t-test of the two groups. However, there was no difference between subgroups in the nature-friendly group, and also in the general group. The K-CNS shows a higher mean when there is more experience and frequency of contact with nature and longer hours of nature-friendly agricultural activities. In particular, agricultural alternative high school 
Table 4. Verification of $\mathrm{K}-\mathrm{CNS}$ differences by sub-group ( $\mathrm{N}=407)$

\begin{tabular}{ccccc}
\hline Sub-group & 1 & 2 & 3 & 4 \\
\hline 1 & 1 & & & \\
2 & $.104^{\mathrm{NS}}$ & 1 & & \\
3 & $.000^{* * *}$ & $.000^{* * *}$ & 1 & \\
4 & $.000^{* * *}$ & $.000^{* * *}$ & $.950^{\mathrm{NS}}$ & 1 \\
$\mathrm{M}$ & 35.42 & 33.05 & 39.55 & 40.05 \\
$\mathrm{SD}$ & 6.62 & 7.14 & 4.43 & 4.72 \\
\multicolumn{5}{c}{$\mathrm{F}=17.253 p<.001$} \\
\hline
\end{tabular}

Note. Sub-group $1=$ general adults $(\mathrm{n}=248) ; 2=$ academic high school students $(n=59) ; 3=$ forest therapists $(n=44) ; 4=$ agricultural alternative high school students $(\mathrm{n}=56)$.

${ }^{\mathrm{NS}}$ Non-significant, ${ }^{*} p<.05,{ }^{* *} p<.01,{ }^{* * *} p<.001$ by Welch's t-test.

students had the mean that was 7 points higher than general high school students, showing a huge gap. Therefore, if students constantly participate in gardening or horticultural activities to interact with nature in the school curriculum, it will lead to positive effects on emotional stability.

\section{K-CNS and gender relations}

We conducted an independent samples t-test to determine the differences in the K-CNS by gender in the general group $(\mathrm{N}=407)$. The analysis results showed that the female subjects had a higher mean than the male subjects, but there was no significant difference (Table 5). It was consistent with the study by Mayer and Frantz (2004) on 60 subjects (31 male, 29 female) of the Oberlin Community, which showed that there was no significant difference between female $(\mathrm{M}=3.76, \mathrm{SD}=0.47)$ and male $(\mathrm{M}=3.54$, $\mathrm{SD}=0.74)$. The female subjects seem to have higher means due to their interest in environmental pollution such as particulate matter or safe foods like genetically modified organisms (GMO) in relation to childcare.

\section{K-CNS and age relations}

To verify whether there is a difference in the K-CNS by age, we conducted a one-way ANOVA on the general group $(n=307)$. We excluded 100 subjects of the nature-friendly group (forest therapists, agricultural alternative high school students) to assume a general circumstance. The analysis results showed that there was a significant difference by
Table 5. Verification of K-CNS differences by gender

\begin{tabular}{cccccc}
\hline Gender & $\mathrm{n}$ & $\mathrm{M}$ & $\mathrm{SD}$ & $t$ & $p$ \\
\hline Male & 178 & 35.59 & 7.02 & & \\
Female & 229 & 36.61 & 6.31 & & $.126^{\mathrm{NS}}$ \\
\hline \multicolumn{7}{r}{ NS Non-significant by Independent Sample t-test. }
\end{tabular}

${ }^{\mathrm{NS}}$ Non-significant by Independent Sample t-test.

Table 6. Verification of K-CNS differences by age $(n=307)$

\begin{tabular}{cccccc}
\hline Age group & 1 & 2 & 3 & 4 & 5 \\
\hline 1 & 1 & & & & \\
2 & $1.00^{\mathrm{NS}}$ & 1 & & & \\
3 & $.994^{\mathrm{NS}}$ & $.988^{\mathrm{NS}}$ & 1 & & \\
4 & $.001^{* * *}$ & $.000^{* * *}$ & $.043^{*}$ & 1 & \\
5 & $.000^{* * *}$ & $.000^{* * *}$ & $.001^{* * *}$ & $.933^{\mathrm{NS}}$ & 1 \\
$\mathrm{M}$ & 32.96 & 32.88 & 33.62 & 38.60 & 39.79 \\
$\mathrm{SD}$ & 7.08 & 5.93 & 4.86 & 6.26 & 5.94 \\
\multicolumn{5}{c}{$\mathrm{F}=17.636^{* * *} p<.001$} \\
\hline
\end{tabular}

Note. Age group $1=$ below $20 ; 2=20-29 ; 3=30-39 ; 4=40-49 ; 5=50$ years or older.

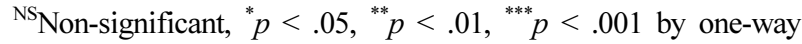
ANOVA test.

age $(\mathrm{F}=22.235, p<.001)$. As Levene's equality of variance conditions were met in the test for homogeneity of variance, we conducted the Scheffe test as a post-hoc test. The result showed that there was not much difference from the $10 \mathrm{~s}$ to $30 \mathrm{~s}$, but the score increased significantly in the 40 s, which was maintained and slightly increased in the 50s (Table 6). Mayer and Frantz (2004) proved that the graduate students group $(\mathrm{M}=3.87, \mathrm{SD}=0.48)$ showed significantly higher results than the high school students group $(\mathrm{M}=3.27, \mathrm{SD}=0.53)$, but in this study, the 20s $(\mathrm{M}=32.88)$ and 10s $(\mathrm{M}=32.96)$ showed similar results. The scores were generally low from the $10 \mathrm{~s}$ to $30 \mathrm{~s}$ because there is little opportunity to encounter nature due to college entrance examination, employment and childcare, and also due to the cultural tendency in which people spend more time on the internet and mobile devices. On the other hand, the scores were high in the 40s-50s because they have much time to encounter nature such as gardening and hiking, and also because they may have been exposed more to nature during their childhood. 


\section{Conclusion}

This study translated the CNS developed by Mayer and Frantz (2004) into Korean, named it as K-CNS and validated the scale. To this end, we conducted a survey on 407 subjects aged 17 to 60 distributed throughout various regions. As a result of conducting an exploratory factor analysis to verify the validity of the K-CNS, 10 items in the single factor were extracted. The reliability of the K-CNS was satisfactory with Cronbach's alpha at .880 .

Construct validity was verified by the positive correlation that the K-CNS had with the NEP scale, MHC-SF, ACLS-CO, and SWLS, and the negative correlation with the SRI-MF. Moreover, we verified the difference in nature connectedness between the nature-friendly group and general group to determine the criterion-related validity of the $\mathrm{K}-\mathrm{CNS}$, and the result showed a significant difference. As a result of the t-test additionally conducted to determine between-group differences, there was no difference by gender. By age, there was not much difference from the 10 s to 30 s, but the score increased significantly in the 40 s, which was maintained and slightly increased in the $50 \mathrm{~s}$ as well. In particular, the K-CNS turned out to be more closely correlated with emotion-related scales such as well-being, compassion, satisfaction with life and stress than the NEP, which proved the need to validate the CNS scale intended for in-depth determination of emotional and empirical connectedness regarding 'unity with nature'.

The limitations of this study are that nearly half (48.15\%) of the participants are high school and college students, and that it is difficult to measure the ecological crisis due to the recently urgent environmental issue of climate change. Further research shall be conducted to develop the CNS for children considering the importance of early education in ecology and environment.

\section{References}

Bratman, G.N., G.C. Daily, B.J. Levy, and J.J. Gross. 2015. The benefits of nature experience: Improved affect and cognition. Landsc. Urban Plan. 138:41-50. https://doi.org/10.1016/j.landurbplan.2015.02.005
Bratman, G.N., J.P. Hamilton, and G.C. Daily. 2012. The impacts of nature experience on human cognitive function and mental health. Ann. N.Y. Acad. Sci. 1249:118-136. https://doi.org/10.1111/j.1749-6632.2011.06400.x

Cho, M.H. and K.H. Cha. 1998. A comparative study across countries for qualities of life. Seoul, Korea: Jipmoondang Publishing.

Choi, S.M., T.Y. Kang, and J.M. Woo. 2006. Development and validation of a modified form of the stress response inventory for workers. J. Korean Neuropsychiatr. Assoc. 45(6):541-553.

Coholic, D.A. 2011. Exploring the feasibility and benefits of arts-based mindfulness-based practices with young people in need: Aiming to improve aspects of self-awareness and resilience. Child Youth Care Forum 40(4):303-317. https://doi.org/10.1007/s10566-010-9139-x

Diener, E.D., R.A. Emmons, R.J. Larsen, and S. Griffin. 1985. The satisfaction with life scale. J. Pers. Assess. 49(1):71-75.

Dunlap, R.E. and K.D. Van Liere. 1978. The "new environmental paradigm". J. Environ. Educ. 9(4):10-19. https://doi.org/10.3200/JOEE.40.1.19-28

Dunlap, R.E., K.D. Van Liere, A.G. Mertig, and R.E. Jones. 2000. New trends in measuring environmental attitudes: measuring endorsement of the new ecological paradigm: A revised NEP scale. J. Soc. Issues 56(3):425-442. https://doi.org/10.1111/0022-4537.00176

Gim, W.S. and K.H. Shin. 2014. The development of the Ajou Compassionate Love Scale: a Korean abbreviation of Sprecher and Fehr's Compassionate Love Scale. Korean J. Health Psychol. 19(1):407-430. https://doi.org/10.173 15/kjhp.2014.19.1.022

Keyes, C.L. 2002. The mental health continuum: From languishing to flourishing in life. J. Health Soc. Behav. 43(2):207-222.

Lee, J.H. 2013. Psycho-property test and validity for Korean version of Nature Relatedness Scale. Doctoral dissertation, Chungbuk National University, Cheongju, Korea.

Lim, Y.J., Y.K. Ko, H.C. Shin, and Y.L Cho. 2012. Psychometric evalucation of the Mental Health ContinuumShort Form (MHC-SF) in South Korean. Korean J. Psychol. Gen. 31(2):369-386. 
Louv, R. 2011. The nature principle: Human restoration and the end of nature-deficit disorder. Chapel Hill, NC: Algonquin Books.

Lumber, R., M. Richardson, and D. Sheffield. 2017. Beyond knowing nature: Contact, emotion, compassion, meaning, and beauty are pathways to nature connection. PloS One 12(5):e0177186. https://doi.org/10.1371/journal.pone.01 77186

Mayer, F.S. and C.M. Frantz. 2004. The connectedness to nature scale: A measure of individuals' feeling in community with nature. J. Environ. Psychol. 24(4):503-515. https://doi.org/10.1016/j.jenvp.2004.10.001

Nisbet, E.K., J.M. Zelenski, and S.A. Murphy. 2009. The nature relatedness scale: Linking individuals' connection with nature to environmental concern and behavior. Environ. Behav. 41(5):715-740. https://doi.org/10.1177/ 0013916508318748

Pretty, J.N. 2004. How nature contributes to mental and physical health. Spiritual. Health Int. 5(2):68-78. https://doi.org/10.1002/shi.220
Sahlin, E. 2014. To stress the importance of nature: Naturebased therapy for the rehabilitation and prevention of stress-related disorders. Acta Universitatis agriculturae Sueciae 2014:98.

Sahlin, E., G. Ahlborg, Jr., J.V. Matuszczyk, and P. Grahn. 2014. Nature-based stress management course for individuals at risk of adverse health effects from work-related stress-effects on stress related symptoms, workability and sick leave. Int. j. Environ. Res. Public Health 11(6):6586-6611.

Schultz, P.W. 2002. Inclusion with nature: The psychology of human-nature relations. In: Psychology of sustainable development (pp. 61-78). Boston, MA: Springer. https://doi.org/10.1007/978-1-4615-0995-0_4

Shin, W.S. 2001. Reliability and factor structure of a Korean version of the new environmental paradigm. J. Soc. Behav. Pers. 16(1):9-18.

Sprecher, S. and B. Fehr. 2005. Compassionate love for close others and humanity. J. Soc. Pers. Relatsh. 22(5):629-651. 